\title{
Synthesis and Magnetic Properties of Nano-sized Mn Ferrite Powder and Film
}

\author{
Woo Hyun Kwon ${ }^{1}$, Jae-Gwang Lee ${ }^{1}$, Young Bae Lee ${ }^{2}$, and Kwang Pyo Chae ${ }^{1 *}$ \\ ${ }^{1}$ Department of Applied Physics, Konkuk University, Chungbuk 380-701, Korea \\ ${ }^{2}$ Department of Physics, Hanzhong University, Kangwon 240-150, Korea
}

(Received 26 October 2010, Received in final form 4 February 2011, Accepted 7 February 2011)

\begin{abstract}
Nano-sized manganese ferrite powders and films, $\mathrm{MnFe}_{2} \mathrm{O}_{4}$, were fabricated by the sol-gel method, and the effects of annealing temperature on the crystallographic and magnetic properties were studied by using $\mathrm{X}$-ray diffractometry, field emission scanning electron microscopy, Mössbauer spectroscopy, and vibrating sample magnetometry. X-ray diffraction spectroscopy of powder samples annealed above $523 \mathrm{~K}$ indicated the presence of spinel structure, and the film samples annealed above $773 \mathrm{~K}$ also had spinel structure. The particle size increased with the annealing temperature. For the powder samples, the Mössbauer spectra annealed above 573 $K$ could be fitted as the superposition of two Zeeman sextets due to the tetrahedral and octahedral sites of $\mathrm{Fe}^{3+}$ ions. Using the Mössbauer subspectrum area ratio the cation distribution could be written as $\left(\mathrm{Mn}_{0.52} \mathrm{Fe}_{0.48}\right)$ $\left[\mathrm{Mn}_{0.48} \mathrm{Fe}_{1.52}\right] \mathrm{O}_{4}$. However the spectrum annealed at $523 \mathrm{~K}$ only showed as a doublet due to a superparamagnetic phase. As the annealing temperature was increased, the saturation magnetization and the corecivity of the powder samples increased, as did the coercivity of film samples.
\end{abstract}

Keywords : Mn ferrite, sol-gel method, Mössbauer spectroscopy, coercivity, saturation magnetization

\section{Introduction}

Spinel soft ferrites are important because they are relatively inert and their properties can be tailored by chemical manipulations. Manganese ferrite, $\mathrm{MnFe}_{2} \mathrm{O}_{4}$, is a technologically important material because of its magnetic permeability and low core losses. Manganese ferrite has a spinel configuration based on a face-centered cubic lattice of oxygen ions with a unit cell consisting of 8 functional units of the type $\left(\mathrm{Mn}_{\mathrm{x}} \mathrm{Fe}_{1-\mathrm{x}}\right)\left[\mathrm{Mn}_{1-\mathrm{x}} \mathrm{Fe}_{1+\mathrm{x}}\right] \mathrm{O}_{4}$. In this formula, the metallic cations in the parentheses occupy the tetrahedral sites, the metallic cations in the brackets occupy the octahedral sites, and $\mathrm{x}$ is defined as an inversion parameter [1].

Numerous studies utilizing a variety of methods have been conducted on the synthesis of Manganese ferrites. In particular, nano-sized ferrites that are contained inside manganese have been widely studied [2-5]. Many physical properties of polycrystalline ferrites depend on their microstructure, which is strongly connected with the preparation conditions. For this reason, studies of the chemical compositions of ferrites are still carried out in order to

*Corresponding author: Tel: +82-43-840-3623

Fax: +82-43-851-4169, e-mail: kpchae@kku.ac.kr optimize their properties. The sol-gel method is a technique for the low temperature synthesis of glass, ceramics and other materials using dip coating or spin coating for the production of thin films. One of the advantages of using the sol-gel method is the lower annealing temperature that enables smaller grained powders to be grown. These ultra fine ferrite particles have been intensively investigated. The sol-gel method can provide a multicomponent oxide with a homogeneous composition, and it has been employed to prepare many high purity oxide powders and films, including some products with spinel type structures [6-8]. In the previous paper we studied the superparamagnetic properties of manganese ferrite powder [9].

In this study we have synthesized manganese ferrite powders and films at various annealing temperatures by the sol-gel method. Their crystallographic and magnetic properties were studied by means of X-ray diffractometry (XRD), field emission scanning electron microscopy (FESEM), Mössbauer spectroscopy and vibrating sample magnetometry (VSM).

\section{Experiment}

$\mathrm{MnFe}_{2} \mathrm{O}_{4}$ ferrite powders and films were prepared by the 
sol-gel method. Measured $3.5 \mathrm{~g}$ samples of $\mathrm{Fe}\left(\mathrm{NO}_{3}\right)_{3} \cdot 9 \mathrm{H}_{2} \mathrm{O}$ $(2.6855 \mathrm{~g})$ and $\mathrm{Mn}\left(\mathrm{NO}_{3}\right) \cdot \mathrm{H}_{2} \mathrm{O}(0.8145 \mathrm{~g})$ were first dissolved in 2-methoxyethanol for 30-50 min with an ultrasonic cleaner. The solution was refluxed at $343 \mathrm{~K}$ for $12 \mathrm{~h}$ in order to gel, and then dried at $373 \mathrm{~K}$ in a dry oven for $24 \mathrm{~h}$. The samples of the dried powders were ground and annealed at various temperatures to determine the growth of the particles. Films were deposited by spin coating on a thermally oxidized $\mathrm{SiO}_{2}$ layer $(200 \mathrm{~nm})$ at $4000 \mathrm{rpm}$ for $30 \mathrm{~s}$, and then dried at $390 \mathrm{~K}$ and $450 \mathrm{~K}$ for $3 \mathrm{~min}$ and $10 \mathrm{~min}$, respectively.

The deposition was repeated 10 times, and the thickness was about $140 \mathrm{~nm}$. The surface microstructure was observed using a FESEM at room temperature. The X-ray diffraction patterns of the powder and the film samples were obtained at room temperature with Cuk $\alpha(\lambda=1.5418 \AA)$ radiation. The Mössbauer spectra of the powders were recorded with a ${ }^{57} \mathrm{Co}$ source in constant acceleration mode to identify the magnetic phase of the manganese ferrite powders. The measurement of the magnetic properties was carried out using a VSM.

\section{Results and Discussion}

The X-ray diffraction patterns of the $\mathrm{MnFe}_{2} \mathrm{O}_{4}$ ferrite powders annealed at various temperatures were shown in a previous paper [9]. The X-ray diffraction measurement shows that all peaks of $\mathrm{MnFe}_{2} \mathrm{O}_{4}$ ferrite powders annealed above $523 \mathrm{~K}$ are consistent with those of a typical spinel structure. The increase of the annealing temperature leads to a sharpening of the major peak, which indicates the growth of the particle size of the spinel powders and improved crystallization. The lattice constant of $\mathrm{MnFe}_{2} \mathrm{O}_{4}$ ferrite powder annealed at $773 \mathrm{~K}$ is $8.475 \AA$. Although the formation of spinel structure starts from $523 \mathrm{~K}$, the considerable broadening of all diffraction peaks suggests that the sizes of the ferrite particles can be expected to be relatively small. This suggests that the low annealing temperature of powders obtained through the sol-gel method has increased the particle size to be comparable to that of powders obtained using the ceramic and wet chemical method. The size of the particles was determined from the diffraction peak broadening by means of the Scherrer equation [10]:

$$
t=\frac{0.9 \lambda}{B \cos \theta_{\mathrm{B}}}
$$

where $\lambda$ represents the $\mathrm{x}$-ray wavelength, $B$ is the half width of the (311) peak, and $\theta_{B}$ is the angle of the (311) peak. As shown in Fig. 1, the particle size of $\mathrm{MnFe}_{2} \mathrm{O}_{4}$ ferrite powders increased with increasing annealing temper-

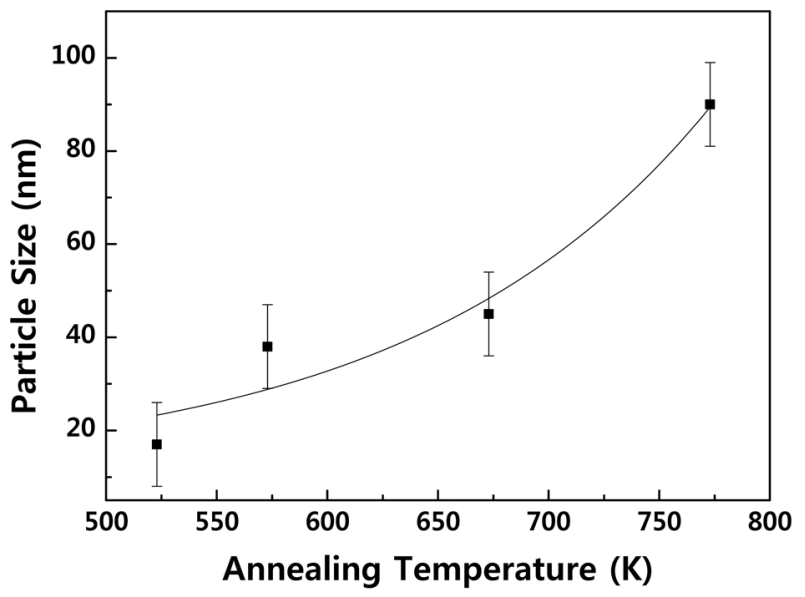

Fig. 1. Variation of the particle size of $\mathrm{MnFe}_{2} \mathrm{O}_{4}$ powder annealed at various temperatures.

ature to $17.45 \mathrm{~nm}(523 \mathrm{~K}), 38.11 \mathrm{~nm}(573 \mathrm{~K}), 45.90 \mathrm{~nm}$ $(673 \mathrm{~K})$, and $90.92 \mathrm{~nm}(773 \mathrm{~K})$.

For the $\mathrm{MnFe}_{2} \mathrm{O}_{4}$ ferrite films, the $\mathrm{X}$-ray diffraction patterns of those annealed at $773 \mathrm{~K}$ are consistent with the typical spinel structure as shown in Fig. 2. The increase of the particle size with increasing annealing temperature is confirmed by FESEM as shown in Fig. 3. All the samples appear to consist of some regular grains with a narrow distribution of particle sizes. The films show smaller particles than those of powders at the same annealing temperature.

The Mössbauer absorption spectra for $\mathrm{MnFe}_{2} \mathrm{O}_{4}$ ferrite powders annealed at different temperatures are measured

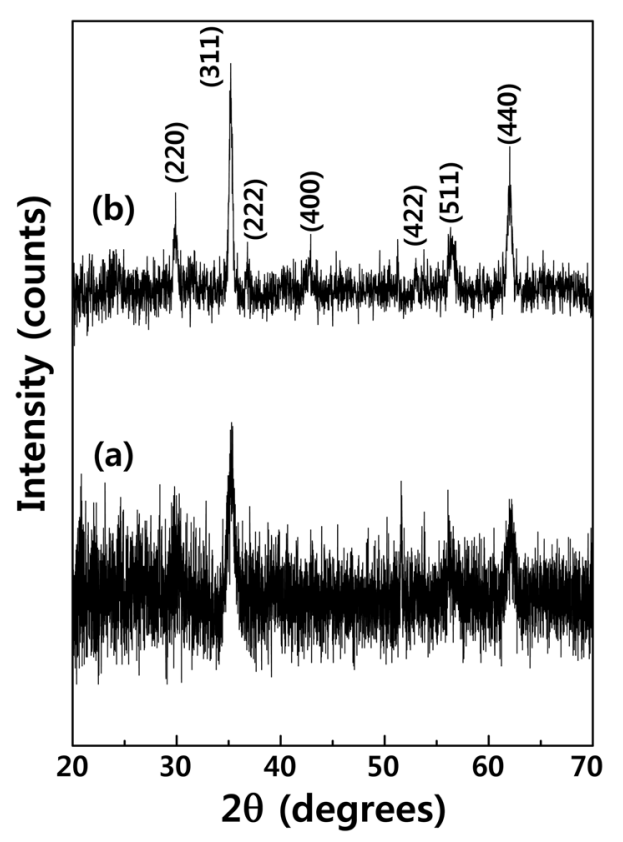

Fig. 2. X-ray diffraction patterns of $\mathrm{MnFe}_{2} \mathrm{O}_{4}$ film annealed at (a) $773 \mathrm{~K}$ and (b) $973 \mathrm{~K}$. 


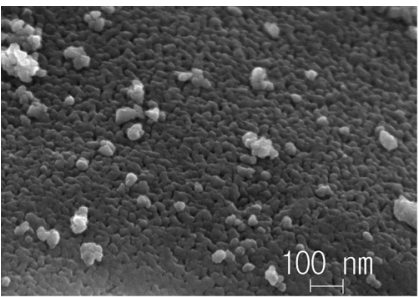

(a)

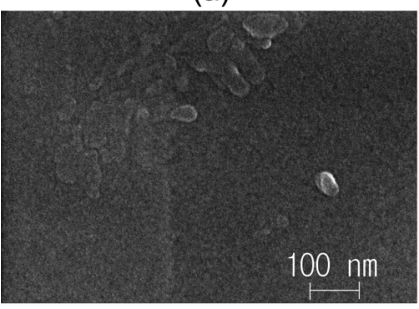

(c)

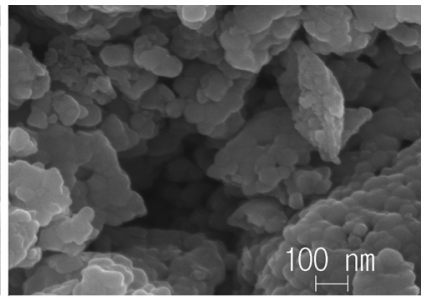

(b)

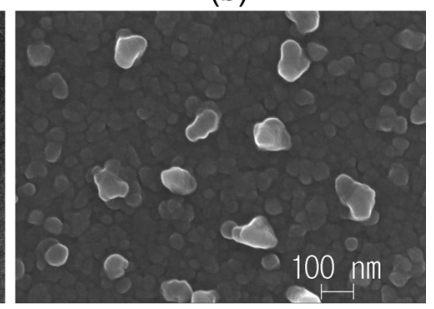

(d)
Fig. 3. FESEM images of $\mathrm{MnFe}_{2} \mathrm{O}_{4}$ powder and film annealed at various temperatures; (a) $573 \mathrm{~K}$ and (b) $773 \mathrm{~K}$ for powders, (c) $773 \mathrm{~K}$ and (d) $973 \mathrm{~K}$ for films.

Table 1. Room temperature Mössbauer parameters of Mn ferrite, $\mathrm{MnFe}_{2} \mathrm{O}_{4}$, powder annealed at various temperatures. $H_{h f}$ is the magnetic hyperfine field, $Q S$ is the quadrupole splitting and $I S$ represents the isomer shift relative to metallic iron at room temperature.

\begin{tabular}{ccccccc}
\hline \hline \multirow{2}{*}{$\mathrm{T}(\mathrm{K})$} & \multicolumn{2}{c}{$H_{h f}(\mathrm{kOe})$} & \multicolumn{2}{c}{$Q S(\mathrm{~mm} / \mathrm{s})$} & \multicolumn{2}{c}{$I S(\mathrm{~mm} / \mathrm{s})$} \\
\cline { 2 - 7 } & A site & B site & A site & B site & A site & B site \\
\hline 773 & 481.4 & 440.5 & 0.001 & 0.004 & 0.404 & 0.302 \\
673 & 477.6 & 437.2 & 0.016 & 0.018 & 0.322 & 0.440 \\
573 & 458.1 & 410.3 & 0.010 & 0.014 & 0.355 & 0.455 \\
523 & - & - & 0.520 & 0.900 & 0.230 & 0.210 \\
\hline
\end{tabular}

at room temperature [11]. The spectra of all samples annealed above $523 \mathrm{~K}$ are fitted with two six-line subspectra that are assigned a tetrahedral A site and octahedral B sites of $\mathrm{Fe}^{3+}$ ions, as shown in Table 1 . The isomer shifts at room temperature for the $\mathrm{A}$ and the $\mathrm{B}$ sites were found to be $(0.230-0.210) \mathrm{mm} / \mathrm{s}$ and $(0.230-0.455) \mathrm{mm} / \mathrm{s}$ relative to the Fe metal, which is consistent with a high-spin $\mathrm{Fe}^{3+}$ charge state. The quadrupole splitting for both the A and the B sites vanished in accordance with the cubic crystal structure. The quadrupole splitting values of the ferromagnetic state are almost 0 , but this was increased in the paramagnetic state. This means that the electric field gradient of the paramagnetic state is larger than that of the ferromagnetic state. The cation distribution depends on many factors, such as the temperature, pressure, composition, and preparation method $[12,13]$. Using the absorption ratio of the Mössbauer subspectra in $\mathrm{MnFe}_{2} \mathrm{O}_{4}$, the cation distribution was determined as follows:

$\left(\mathrm{Mn}_{0.52} \mathrm{Fe}_{0.48}\right)\left[\mathrm{Mn}_{0.48} \mathrm{Fe}_{1.52}\right] \mathrm{O}_{4}$

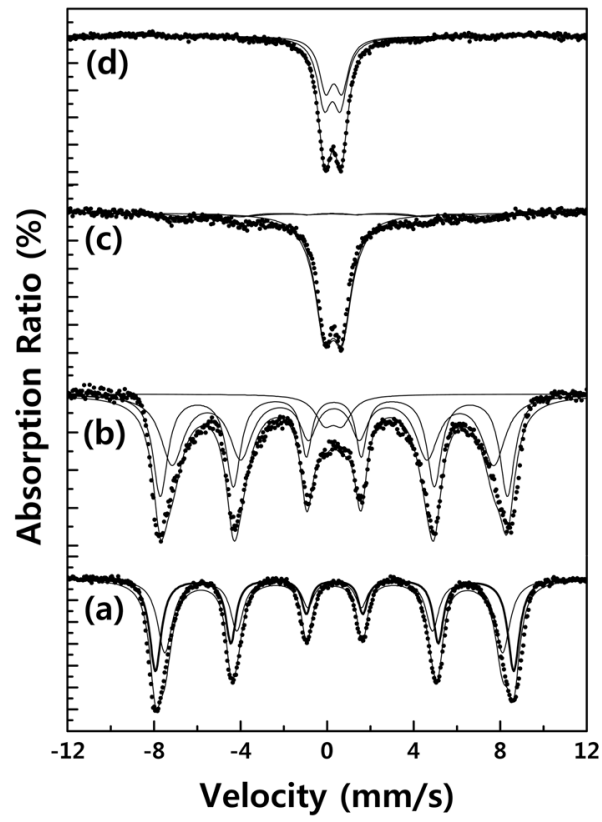

Fig. 4. Mössbauer spectra of $\mathrm{MnFe}_{2} \mathrm{O}_{4}$ powder annealed at $523 \mathrm{~K}$ at low temperatures; (a) $4.2 \mathrm{~K}$, (b) $50 \mathrm{~K}$, (c) $180 \mathrm{~K}$, and (d) $295 \mathrm{~K}$.

This can be compared with $\left(\mathrm{Zn}_{\mathrm{x}} \mathrm{Fe}_{1-\mathrm{x}}\right)\left[\mathrm{Mn}_{1-\mathrm{x}} \mathrm{Fe}_{1+\mathrm{x}}\right] \mathrm{O}_{4}$ for a Zn-Mn ferrite [14].

The Mössbauer spectrum for the powder annealed at $523 \mathrm{~K}$, as shown in Fig. 4(d), is attributed to the paramagnetic behavior, due to the small particle size and the superparamagnetic properties, which were confirmed at low temperature Mössbauer spectra [9]. The spectrum slowly changed from doublets at $180 \mathrm{~K}$ to Zeeman sextets below $50 \mathrm{~K}$.

The magnetic properties of the $\mathrm{MnFe}_{2} \mathrm{O}_{4}$ ferrite powders and films were determined at room temperature using a vibrating sample magnetometer. For $\mathrm{MnFe}_{2} \mathrm{O}_{4}$ ferrite powder the saturation magnetization $\left(M_{S}\right)$ and the coercivity $\left(H_{C}\right)$ increased with increasing annealing temperature as shown in Table 2. The increments of the saturation magnetization and the coercivity of the samples with increasing annealing temperature may come from increasing the particle size. In order to determine the magnetic easy axis of $H_{c}$ of the film sample, we measured the system under conditions of

Table 2. Saturation magnetization and coercivity of $\mathrm{MnFe}_{2} \mathrm{O}_{4}$ powder annealed at various temperatures.

\begin{tabular}{ccc}
\hline \hline $\mathrm{T}(\mathrm{K})$ & $M_{S}(\mathrm{emu} / \mathrm{g})$ & $H_{C}(\mathrm{Oe})$ \\
\hline 523 & 16.2 & 41.7 \\
573 & 45.0 & 41.7 \\
673 & 47.2 & 125.4 \\
773 & 53.9 & 124.6 \\
\hline
\end{tabular}




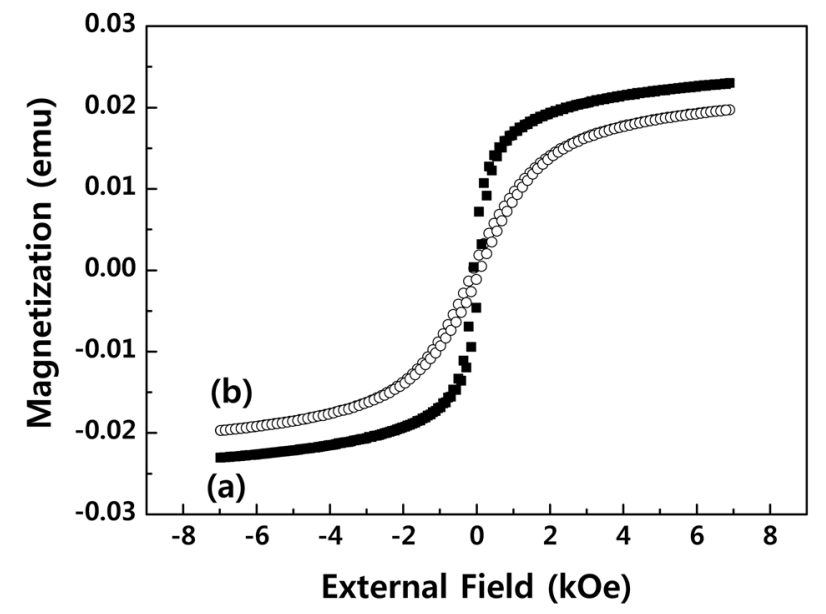

Fig. 5. Hysteresis curve of $\mathrm{MnFe}_{2} \mathrm{O}_{4}$ film annealed at $773 \mathrm{~K}$ under external fields; (a) perpendicular and (b) parallel.

both parallel and perpendicular fields. Fig. 5 shows the hysteresis curves of the $\mathrm{MnFe}_{2} \mathrm{O}_{4}$ ferrite films annealed at $773 \mathrm{~K}$ in the maximal field of $7 \mathrm{kOe}$. There is no significant difference in $M-H$ curves, which indicates ferrite grains in the film oriented randomly and their easy axis located without any preferred direction. The coercivity increased with increasing annealing temperature as 29 Oe $(673 \mathrm{~K}), 88 \mathrm{Oe}(773 \mathrm{~K})$, and $95 \mathrm{Oe}(873 \mathrm{~K})$ under the parallel field, and 29 Oe $(673 \mathrm{~K}), 96 \mathrm{Oe}(773 \mathrm{~K})$, and 93 Oe $(873 \mathrm{~K})$ under the perpendicular field, respectively. The coercivities of the films are small in comparison to those of the powders at the same annealing temperature. This can be related to the particle size, since the particle size of the films are smaller than those of the powders at the same annealing temperature.

\section{Conclusion}

Nano-sized manganese ferrite, $\mathrm{MnFe}_{2} \mathrm{O}_{4}$, powders and films were fabricated by the sol-gel method. The effects of annealing temperature on the crystallographic and magnetic properties of the sample were studied.

X-ray diffraction spectroscopy of powder samples annealed above $523 \mathrm{~K}$ indicated the presence of spinel structure, and film samples annealed above $773 \mathrm{~K}$ also had spinel structure. The particle size increased with the annealing temperature.
For the powder sample, the Mössbauer spectra annealed above $573 \mathrm{~K}$ could be fitted as the superposition of two Zeeman sextets due to the tetrahedral and octahedral sites of $\mathrm{Fe}^{3+}$ ions. Using the Mössbauer subspectrum area ratio the cation distribution could be written as $\left(\mathrm{Mn}_{0.52} \mathrm{Fe}_{0.48}\right)$ $\left[\mathrm{Mn}_{0.48} \mathrm{Fe}_{1.52}\right] \mathrm{O}_{4}$. However the spectrum annealed at 523 $\mathrm{K}$ only showed as a doublet due to the superparamagnetic phase.

The magnetic behavior of the powder samples showed that the saturation magnetization and the coercivity increased with increasing annealing temperature. For the $\mathrm{MnFe}_{2} \mathrm{O}_{4}$ ferrite films, the coercivity also increased with increasing annealing temperature.

\section{Acknowledgements}

This work was supported by Konkuk University in 2011.

\section{References}

[1] N. N. Greenwood and T. C. Gibb, Mössbauer spectroscopy, Chapman and Hall Ltd. London, (1971) p.265.

[2] A. H. Qureshi, J. Cryst. Growth 286, 365 (2006).

[3] J. Nie, H. Li, Z. Feng, and H. He, J. Magn. Magn. Mater. 265, 172 (2003).

[4] M. K. Shobana, S. Sanka, and V. Rajendran, Mater. Chem. Phys. 113, 10 (2009).

[5] M. H. Mahmoud, Solid State Ionics 176, 1333 (2005).

[6] K. Oda, T. Yoshio, K. hirata, K. O. Oka, and K. Takabashi, J. Jpn. Soc. Powder: Powder Metall. 29, 170 (1982).

[7] K. P. Chae, J. G. Lee, W. K. Kim, and Y. B. Lee, J. Magn. Magn. Mater. 248, 236 (2002).

[8] K. G. Brooks and V. R. W. Amarakoon, J. Am. Ceram. Soc. 53, 3965 (1998).

[9] S. W. Lee, J. K. Lee, K. P. Chae, W. H, Kwon, and C. S. Lee, J. Kor. Mag. Soc. (in Korean) 19, 57 (2009).

[10] B. D. Cullity, Elements of X-Ray Diffraction, AddisonWesley Co. Readings, MA (1978) p.102.

[11] W. H. Kwon, Ph. D. Thesis, Konkuk University (2010) p.79.

[12] R. K. Datta and B. Roy, J. Am. Ceram. Soc. 50, 578 (1967).

[13] N. Yamamoto, S. Kawano, N. Achwa, M. Kiyama, and T. Takada, Japan. J. Appl. Phys. 12, 1830 (1973).

[14] A. S. Albuquerque, J. D. Ardisson, and W. A. A. Macedo, J. Appl. Phys. 87, 4352 (2000). 